Review

\title{
Major Pathophysiological Correlations of Rosacea: A Complete Clinical Appraisal
}

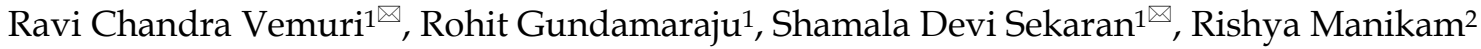 \\ 1. Department of Medical Microbiology, Faculty of Medicine, University of Malaya, Kuala Lumpur 50603, Malaysia \\ 2. Department of Trauma and Emergency, University Malaya Medical Center, 59100 Kuala Lumpur, Malaysia.
}

\begin{abstract}
$\square$ Corresponding author: Ravi Chandra Vemuri, Department of Medical Microbiology, Faculty of Medicine, University of Malaya, Kuala Lumpur 50603, Malaysia. Email: ravichandra@siswa.um.edu.my; ravichandra1788@gmail.com. Prof. Dr. Shamala Devi Sekaran, Department of Medical Microbiology, Faculty of Medicine, University of Malaya, Kuala Lumpur 50603, Malaysia. Email: shamala@um.edu.my; shamalamy@yahoo.com
\end{abstract}

() 2015 Ivyspring International Publisher. Reproduction is permitted for personal, noncommercial use, provided that the article is in whole, unmodified, and properly cited. See http://ivyspring.com/terms for terms and conditions.

Received: 2014.09.22; Accepted: 2015.01.08; Published: 2015.05.05

\begin{abstract}
Background: Rosacea is a characteristic cutaneous disorder with a diverse clinical manifestations ranging from facial vascular hyper-reactivity to sebaceous gland hyperplasia. Many theories on pathophysiology of rosacea were proposed over the past decade, however the pathogenicity is poorly understood.

Aim: To review the evidence on different pathophysiological correlations of rosacea.

Methods: A literature search was conducted for studies published between 1990 to March 2014. The inclusion criteria was pathophysiology, randomized controlled trials, controlled trials on rosacea.

Results: Out of 5141 articles, 14 high quality studies met all the selection criteria. Of 14 articles, 5 are randomized control trials (RCTs), 2 are controlled trial, 3 comparative trials, 2 observational trials, 1 prospective and 1 diagnostic trial. The studies were categorized into two groups: the trigger factors and sub-types \& symptoms. Of 7 high quality studies, 4 provided strong evidence that immune responses causing disease triggered by external/internal factors such as sunlight, food and chemical agents, 3 trials provided significant evidence of microorganisms as causative agents. The remaining trials did not provide significant evidences on pathophysiology.

Conclusion: Vasculature, chronic inflammatory responses, environmental triggers, food and chemicals ingested and microorganisms either alone or in combination are responsible for rosacea. Many promising drugs are under various phases of clinical trials and interestingly, probiotics could also possibly be used as one of the treatment option.
\end{abstract}

Key words: Rosacea; pathophysiology; vasculature; Chronic Inflammation; randomized control trials.

\section{Introduction}

Rosacea is a characteristic condition affecting skin by causing facial erythema or redness. Around 1 in 10 people in the world are affected by rosacea. It is a chronic, inflammatory disease which is poorly understood due to its intricate reason of cause and onset [1]. The disease affects the convexities of central face, firstly by triggering the redness on your nose, followed by cheeks, chin, and forehead, by causing swelling and skin sores that look like acne. It can also cause burning sensation and soreness in the eyes [1-2]. In more severe cases, the skin can become thicker and enlarge on or around the nose and small blood vessels in the facial skin become visible [3]. The disease can be triggered by certain psychological factors like stress and exposure to certain environment or allergens [4-5]. Rosacea has resemblances with acne and other skin disorders [2]. As with acne, there are some microorganisms that seem to play a role in symptoms. 
However, it is important to realize that rosacea is not "infectious," and cannot be transmitted from one person to another. From the recent studies it is revealed that people with fair-skin are more prone to rosacea [6]. It is more common in women, but the symptoms are often more severe in men. The symptoms tend to recur, usually intermittent but can progressively lead to permanently flushed or red (colour) skin [7], as the skin may fail to return to its normal colour and the enlarged blood vessels and pimples arrive in time. The latter may be described as high colour and is associated with the development of permanent telangiectasia [8]. Additionally, there are individual reports of facial edemas and gritty eyes. Rosacea may rarely reverse itself and generally lasts for years, and, if untreated, it tends to gradually worsen [9].

The onset of the disease could be from childhood or early teen and exacerbates in adulthood due to change in lifestyles, food, psychological factors. The symptoms of rosacea were also reported after excess intake of alcohol but not specific [10]. The exact cause and mechanism of pathogenicity is still unknown, all the proposed mechanisms were based on sheer observations or correlations.

\section{Methods}

A systematic literature review was conducted of peer-reviewed articles published between 1990 and March 2014 in the following databases: EMBASE, PubMed and the Cochrane Central Register of Controlled Trials (CENTRAL). The following search terms were entered: "rosacea or pathophysiology or randomized controlled trials or controlled trials." Reference lists within individual studies and review papers were screened to retrieve relevant studies. The following general inclusion criteria were applied: (i) Types of study design: RCTs and other (ii) experimental studies. Comparison groups included no treatment or other interventions. We excluded abstracts, dissertations, studies involving trials with post-test only design, trials including pathophysiology intervention as a small component of health promotion programmes, animal studies, studies lacking outcomes related to the objectives of this review as well as non-English articles.

\section{Results}

The literature search yielded 5141(n) articles from various databases with 2461 articles from PubMed, 1461 articles from EMBASE, 1000 articles from MEDLINE®. Cochrane CENTRAL was also used for the search of literature, which yielded 209 completed and on-going articles. 10 articles were considered from other sources. The articles left after duplicates are removed and total articles screened are 2680. Applying inclusion and exclusion criteria, 2627 articles were excluded, leaving 53 full-text articles under eligibility criterion. 35 full-text articles were excluded from selected 53, as they do not fit for the literature. 14 full-text research articles were included for high quality synthesis. Figure 1 depicts the flow diagram of selection process. Out of 14 articles, 5 are randomized control trials (RCTs), 2 are controlled trial, 3 comparative trials, 2 observational trials, 1 prospective and 1 diagnostic trial. The 14 studies selected are conducted all over the world, 5 trials are from USA, U.K (with 1 multicenter) and 3 trials are from France, and one each from Ireland, Germany, Croatia, Georgia, Italy and Libya. The sample size from all the studies ranging from $n=20$ to $n=504$. Included trials have got subjects from young to middle age, which helped us to correlate the occurrence of the disease in different age groups. Table 1 describes the detailed description of trials included.

Studies were grouped into two key intervention areas: pathophysiology based on various trigger factors (Sunlight, microorganisms, chemical and food ingested, immune responses) and other based on specific symptoms \& sub-types. Within these groups, the quality synthesis of evidence is provided by using a narrative approach. Out of 14 trials, 6 RCTs investigated on various trigger factors and the rest of them are based on the symptoms and sub-types. The study period among selected studies varied from 4 weeks to 12 months. Among all the studies, only one was multicenter study by Casas et al. [25] conducted across the USA $(n=98)$ on Demodex, immune responses in rosacea condition. 3 studies used the surgical procedures, blood samples of the patient to measure the T-cell responses, peroxidase levels and inflammation levels $[19,32,48]$. Only one study was an observational, cross-sectional survey conducted on clinical association and disease progression between rosacea sub-types [46]. The adherence rate in all studies was measured, an average of $88 \%$ (range: $60-100 \%$ ) of participants were examined till the end of the trials. The studies used different measurement parameters like biopsy specimens immuno-staining, T-cell response from blood samples of patients and HCs, cross-sectional surveys, reactive oxygen species (ROS) measurement by superoxide dismutase (SOD) \& glutathione peroxidase (GPX), ferritin levels were measured by serum peroxidases and ant oxidative levels from blood samples [36, 39, 48]. For measuring the presence of the gut bacteria, the patients are lactulose and glucose breath tests [67]. In some of the studies, the investigators used the overall assessment of inflammatory lesion severity was expressed as a 7-point static score, ranging from 0 (clear) to 7 (severe), ac- 
cording to an investigator's global assessment (GA) $[39,48,68]$.

The statistical analysis of the results from all the studies were performed using various versions of SPSS ${ }^{\circ}$ (11-22), Graph pad prism by analysis of variance (ANOVA), independent $t$-test, student t-test etc.

\section{Effects of various trigger factors}

Proposed trigger factors are grouped into the following categories based on the various trials performed [11]: vasculature, climatic exposures, degen- eration of dermal matrix, chemicals and ingested agents, microbial organisms, ferritin levels in body, influence of reactive oxidative species. However, the main reason causing the disease is still unknown. Also the disease progression among the subtypes (erythemato-telangiectatic, papulopustular (PPR), phymatous, and ocular) could be either by a single factor or combination of factors [4, 15]. Consequently, rosacea-prone persons must have an inherent sensitivity to these ubiquitous triggers [12].

Table 1: Detailed description of trials

\begin{tabular}{|c|c|c|c|c|}
\hline Author & Trial type & Sample size \& description & Length & Outcome/Result \\
\hline $\begin{array}{l}\text { Jarmuda et al } \\
\text { (Ireland) } \\
{[25]}\end{array}$ & $\begin{array}{l}\text { Controlled trial on Demodex } \\
\text { levels on face of patients }\end{array}$ & $\mathrm{n}=127, \mathrm{R}=75, \mathrm{HC}=52$ & 15 weeks & $\begin{array}{l}\text { Demodex } \uparrow \text { in patients } \\
(\mathrm{P}=0.0001)\end{array}$ \\
\hline $\begin{array}{l}\text { Sherif et al } \\
\text { (Libya) } \\
{[27]}\end{array}$ & $\begin{array}{l}\text { Randomized controlled trial on } \\
\text { H. pylori }\end{array}$ & $\mathrm{n}=36$, Mean age $\pm \mathrm{SD}=37.8 \pm 6.6$ years & 21 weeks & $\begin{array}{l}\text { Sun exposure and H. Pylori } \\
\text { have possibly have role in } \\
\text { Rosacea. }(P=0.005)\end{array}$ \\
\hline $\begin{array}{l}\text { Brown et al } \\
\text { (USA) } \\
{[48]}\end{array}$ & $\begin{array}{l}\text { Comparative analysis (Rosacea } \\
\text { (R) \& Cutaneous Lupuserythem- } \\
\text { atous (LE)) }\end{array}$ & $\begin{array}{l}\mathrm{n}=57, \mathrm{R}=27 ; \mathrm{LE}=30 \\
\text { Average age }= \\
(55.5 \text { vs } 42.3 \text { years } \\
P=.0029)\end{array}$ & 6 months & $\begin{array}{l}\text { T-Cell mediated responses } \\
\text { have significant role in } R \text { and } \\
\text { LE. }\end{array}$ \\
\hline $\begin{array}{l}\text { Tisma et al. } \\
\text { (Croatia) } \\
{[36]}\end{array}$ & $\begin{array}{l}\text { Randomized controlled trial on } \\
\text { serum peroxides \& ferritin levels }\end{array}$ & $\begin{array}{l}\mathrm{n}=71, \mathrm{R}=60 ; \mathrm{HC}=11 \\
\text { Mean age }=30 \text { to } 70 \text { years }\end{array}$ & 6 months & $\begin{array}{l}\text { Serum peroxides } \uparrow \& \text { serum } \\
\text { total anti-oxidative potential } \\
\text { levels } \downarrow \text { in } \mathrm{R} \text { v's } \mathrm{HC}(P=.05)\end{array}$ \\
\hline $\begin{array}{l}\text { Bakar et al. } \\
\text { (Turkey) } \\
{[39]}\end{array}$ & Controlled trials on ROS levels & $\begin{array}{l}\mathrm{n}=42, \mathrm{R}=17, \mathrm{HC}=25 \\
\text { Mean } \pm \mathrm{SD} \text { age } 50.3 \pm 19,15.1 \text { years. }\end{array}$ & 6 weeks & $\begin{array}{l}\text { ROS levels } \uparrow \text { in rosacea pa- } \\
\text { tients than in HC }\end{array}$ \\
\hline $\begin{array}{l}\text { Cribier et al. } \\
\text { (France) } \\
{[19]}\end{array}$ & $\begin{array}{l}\text { Diagnostic trial on Pathophysi- } \\
\text { ology of Rosacea }\end{array}$ & $\begin{array}{l}\mathrm{n}=86 \\
\text { mean age }=25 \text { to } 49 \text { years }\end{array}$ & 3 months & $\begin{array}{l}\text { Vasculature and Inflamma- } \\
\text { tion primary factors in } \\
\text { Rosacea }\end{array}$ \\
\hline $\begin{array}{l}\text { LE Heuzey et al. } \\
\text { (France) } \\
{[21]}\end{array}$ & $\begin{array}{l}\text { Randomized controlled trial on } \\
\text { Amiodarone on skin (red- } \\
\text { ness/flush) }\end{array}$ & $\begin{array}{l}\mathrm{n}=504, \mathrm{CI}=95 \% \\
\text { Middle-aged patients }\end{array}$ & 12 months & $\begin{array}{l}\mathrm{HR}=0.80 ; 95 \% \\
\mathrm{CI} 0.60-1.07 ; \mathrm{P}=0.129 \\
\text { Redness } \uparrow\end{array}$ \\
\hline $\begin{array}{l}\text { Tsiskarishvili } \\
\text { et al. } \\
\text { (Georgia) } \\
\text { [49] }\end{array}$ & $\begin{array}{l}\text { Observational trial on early stage } \\
\text { treatment }\end{array}$ & $\begin{array}{l}\mathrm{n}=50, \mathrm{R}=25, \mathrm{HC}=25 \\
\text { mean age }=25 \text { to } 49 \text { years }\end{array}$ & 12 months & $\begin{array}{l}\text { Beta-blockers and Rozaliak } \\
\text { effective for treatment }\end{array}$ \\
\hline $\begin{array}{l}\text { Tan J et al. } \\
\text { (Germany) } \\
{[46]}\end{array}$ & $\begin{array}{l}\text { Observational cross-sectional } \\
\text { survey on clinical association \& } \\
\text { progression b/w sub-types }\end{array}$ & $\mathrm{n}(\mathrm{R})=135$ & 3 months & $\begin{array}{l}\text { Disease progression amongst } \\
\text { associated sub-types. }(P= \\
0.005)\end{array}$ \\
\hline $\begin{array}{l}\text { Guzman-Sanchez } \\
\text { et al. } \\
\text { (USA) } \\
{[18]}\end{array}$ & $\begin{array}{l}\text { Comparative trial to assess heat } \\
\text { pain thresholds and skin blood } \\
\text { flow }\end{array}$ & $\begin{array}{l}\mathrm{n}=24, \mathrm{R}=16 \\
\mathrm{HC}=8\end{array}$ & 5 weeks & $\begin{array}{l}\text { Enhanced sensitivity to } \\
\text { noxious heat stimuli/blood } \\
\text { flow in rosacea-affected skin. } \\
P<.05 \text {. }\end{array}$ \\
\hline $\begin{array}{l}\text { Casas et al. } \\
\text { (France) } \\
{[24]}\end{array}$ & $\begin{array}{l}\text { Prospective/multicenter trial on } \\
\text { Demodex, Rosacea \& immune } \\
\text { responses. }\end{array}$ & $\begin{array}{l}\mathrm{n}=98, \mathrm{R}=50 \\
\mathrm{HC}=48\end{array}$ & 12 months & $\begin{array}{l}\text { D. folliculorum density was } \\
5.7 \text { times } \uparrow \text { in rosacea patients } \\
\text { than in healthy volunteers. } \\
P<0.05 \text {. }\end{array}$ \\
\hline $\begin{array}{l}\text { Smith et al. } \\
\text { (USA) } \\
{[50]}\end{array}$ & $\begin{array}{l}\text { Controlled trial on vascular } \\
\text { endothelial receptor (VEGF) } \\
\text { expression in rosacea }\end{array}$ & $\begin{array}{l}\mathrm{n}=20(\mathrm{R}) \\
\text { Mean age }=25-35 \text { years }\end{array}$ & 4 weeks & $\begin{array}{l}\text { VEGF-ligand binding in } \\
\text { rosacea could contribute } \\
\text { vascular \& cellular changes }\end{array}$ \\
\hline $\begin{array}{l}\text { Coda et al. } \\
\text { (USA, U.K) } \\
{[32]}\end{array}$ & $\begin{array}{l}\text { Randomized multicenter on role } \\
\text { of cathelicidin in rosacea }\end{array}$ & $\begin{array}{l}\mathrm{n}=60(\mathrm{R}=55) \\
\mathrm{HC}=5 \\
\text { age }=18-40 \text { years }\end{array}$ & 16 weeks & $\begin{array}{l}\text { Cathelicidin } \uparrow \& \text { serine pro- } \\
\text { tease activity } \uparrow \text { in rosacea } \\
\text { patients. }\end{array}$ \\
\hline $\begin{array}{l}\text { Parodi et al. } \\
\text { (Italy) } \\
{[66]}\end{array}$ & $\begin{array}{l}\text { Randomized Controlled trial on } \\
\text { gut bacteria }\end{array}$ & $\begin{array}{l}\mathrm{n}=113(\mathrm{R}=53), \text { mean age, } 52 \pm 15 \text { years. } \\
\mathrm{HC}=60 \text { mean age, } 49 \pm 11 \text { years; } 82 \\
\text { women, } 31 \text { men. }\end{array}$ & 9 months & $\begin{array}{l}\text { Gut bacteria } \uparrow \text { in rosacea } \\
\text { patients when compared to } \\
\text { HCs. Rifaximin drug therapy } \\
\text { was given to rosacea patients } \\
\text { and disease } \downarrow\end{array}$ \\
\hline
\end{tabular}

$\mathbf{N}=$ Total number of patients; $\mathbf{R}=$ Rosacea; $\mathbf{H C}=$ Healthy control; $\mathbf{H R}=$ hazard ratio; $\mathbf{P}=$ Significance; $\mathbf{C I}=$ confidence interval; $\uparrow=$ High; $\downarrow=$ Low. 


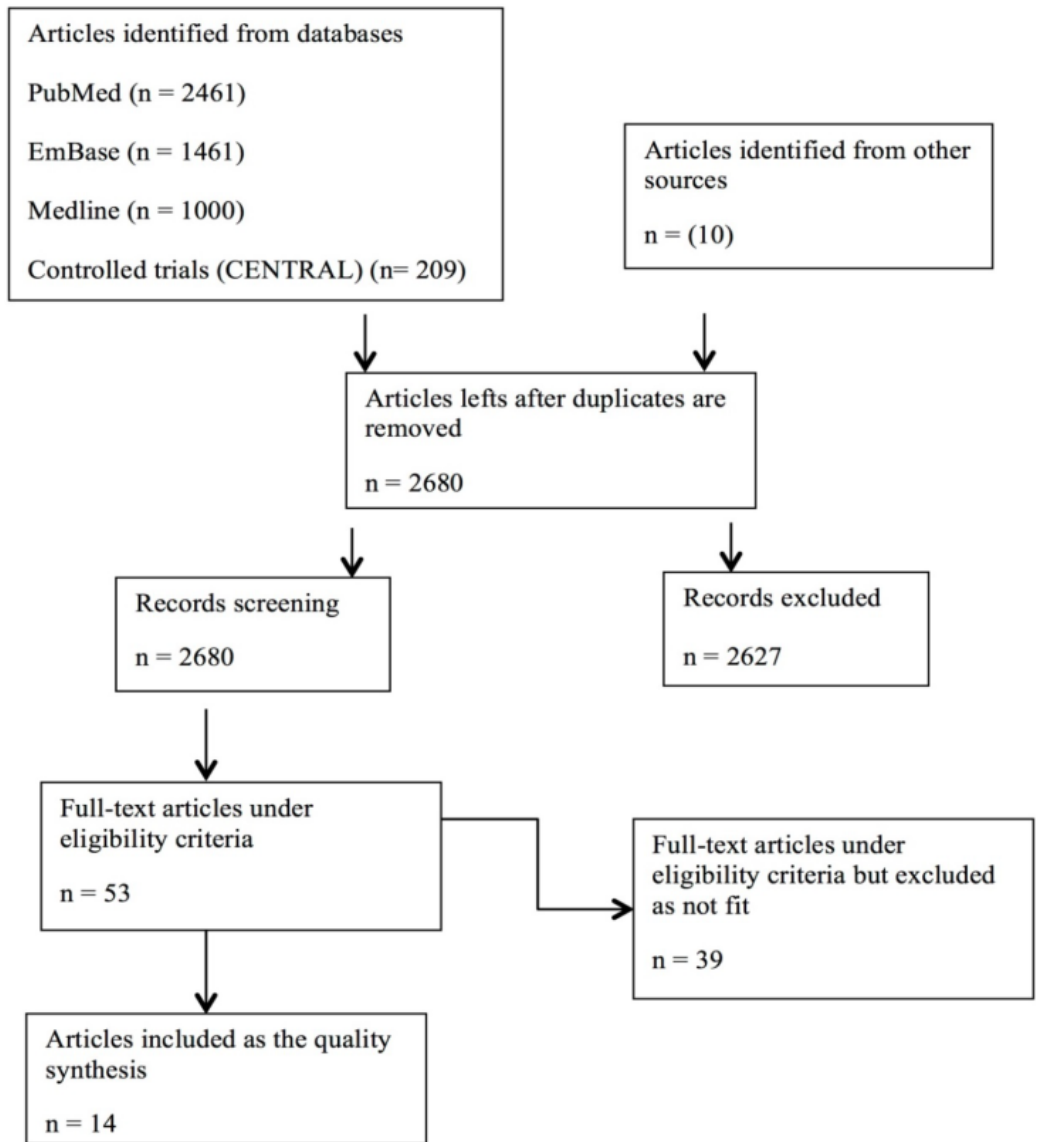

Figure 1: Flow diagram for selection process.

\section{Climatic Exposure}

Exposure to harsh climatic conditions damages cutaneous blood vessels and dermal connective tissue $[13,14]$. Facial convexities and flare during rosacea could possibly occur due to exposure to solar irradiation [14]. Relation to heat stimuli due to sunlight exposure and rosacea was shown in the study conducted by Guzman-Sanchez et al [18].

\section{Vasculature}

Flushing associated with rosacea is possibly caused by increased blood flow to blood vessels which are closer to the surface of the face [18]. And also, hyperthermia by vasodilation is thought to be exaggerated in rosacea patients [12].

\section{Degeneration of dermal layers}

Rosacea involves in the damage of endothelium and degeneration of the dermal matrix [16]. But the facts little known are whether the initial damage is in the dermal matrix and leads to poor tissue support of cutaneous vessels. After which the pooling of serum occurs, possibly giving rise to the inflammatory mediators, and metabolic waste. It could also be like the initial abnormality exists in the cutaneous vasculature
[15-17] and followed by vascular leakage and delayed clearance of serum proteins, inflammatory mediators, and metabolic waste, thus resulting in matrix degeneration [17].

\section{Perivascular inflammation}

An inflammatory penetrate could exist in a perivascular location. The evidence is however conflicting regarding which location predominates [19]. For understanding the perivascular inflammation phenomena, more studies need to be designed to categorize subtypes of rosacea depending on the sub-classification.

\section{Foods, therapeutics and other chemical agents}

The excessive intake of processed and ready to use food and hot beverages are traditionally thought to trigger flushing in patients with rosacea [19]. However, most of the evidence does not support that the dietary factors play a central role in the pathogenesis. And also, specific medications such as anti-arrhythmic drugs (amiodarone) have proven to play a vital role in the disease pathogenicity [21]. Apart the drugs, any high intake of useful vitamins such as B-6 and B-12 may cause reddish flares for patients with rosacea [10, 20-21]. 


\section{Microorganism borne}

Demodex Folliculorum (Demodex) mites that normally inhabit human hair follicles may play a vital role in the pathogenesis of rosacea. Some studies suggest that Demodex invades the skin regions that are affected in rosacea, such as the nose and cheeks [22]. Research also suggests that an immune response of T-cell occurs at the site of Demodex antigens in patients with rosacea [23]. However, the conflicting evidence indicates that Demodex does not induce an inflammatory response in patients with rosacea, as it is also found in large numbers of healthy individuals without rosacea [24, 25]. And also, inconclusive evidence suggests that there is a possible association of Helicobacter pylori with the aetiology of rosacea [26]. However, many of the studies have not controlled for confounding variables that influence $H$. pylori prevalence, such as age, socioeconomic status, sex and certain medications [27, 66]. Furthermore, these studies were not statistically significant to account for the ubiquitous nature of $H$ pylori and also demodex infection.

\section{Role of Antimicrobial peptides}

Antimicrobial peptides (AMPs) have an important role in rosacea pathogenicity. Being the small molecular weight proteins, they are the face of innate immunity. AMPs are proven to show a wide variety of antimicrobial activity against bacteria and virus [28, 45]. They have been inducted in the pathogenesis of many inflammatory skin diseases as the first line of defence upon injury or infection of the skin [46-47]. The most common types of AMPs are cathelicidins and $\beta$-defensins. The evidence based on the recent research shows the high level expression of cathelicidins in individuals affected by rosacea [29-30]. The presence of human cathelicidins, specifically, human cationic antimicrobial protein, hCAP-18/LL-37 has been found in high numbers in rosacea patients. The cathelicidin, hCAP/LL-37 is not only expressed in leukocytes, lymphocytes but also effects vascular endothelial layer by modulating the vascular endothelial growth factor (VEGF) [31-32]. The researchers induced LL-37 and its novel peptides into mice, which gave rise to inflammatory responses, telangiectasia and erythema. This output led researchers postulate that an excess of cathelicidins combining with abnormal processing caused disease [34].

\section{Influence of Reactive Oxygen species}

The process of neutrophils releasing the reactive oxygen species (ROS) as an early inflammatory response is postulated to have important role in rosacea [35]. ROS leading to oxidative tissue damage is explained by the free radicals such as superoxide anions and hydroxyl radicals, in addition to other reactive molecules, such as molecular oxygen, hydrogen peroxide $[39,40]$. The following are several mechanisms which state how ROS result in skin inflammation (Figure 2) [40-43]:

- Inactivation of natural defenses caused by oxidant stress from ROS.

- Change of the lipid balance in rosacea patients, which in normal proportions would suppress the creation of ROS.

- The production of cytokines and other inflammatory mediators by keratinocytes, fibroblasts.

- The endothelial cells damaged by ROS and,

- The generation of ROS by cathelicidins which are found in greater amounts in the facial skin of affected patients.

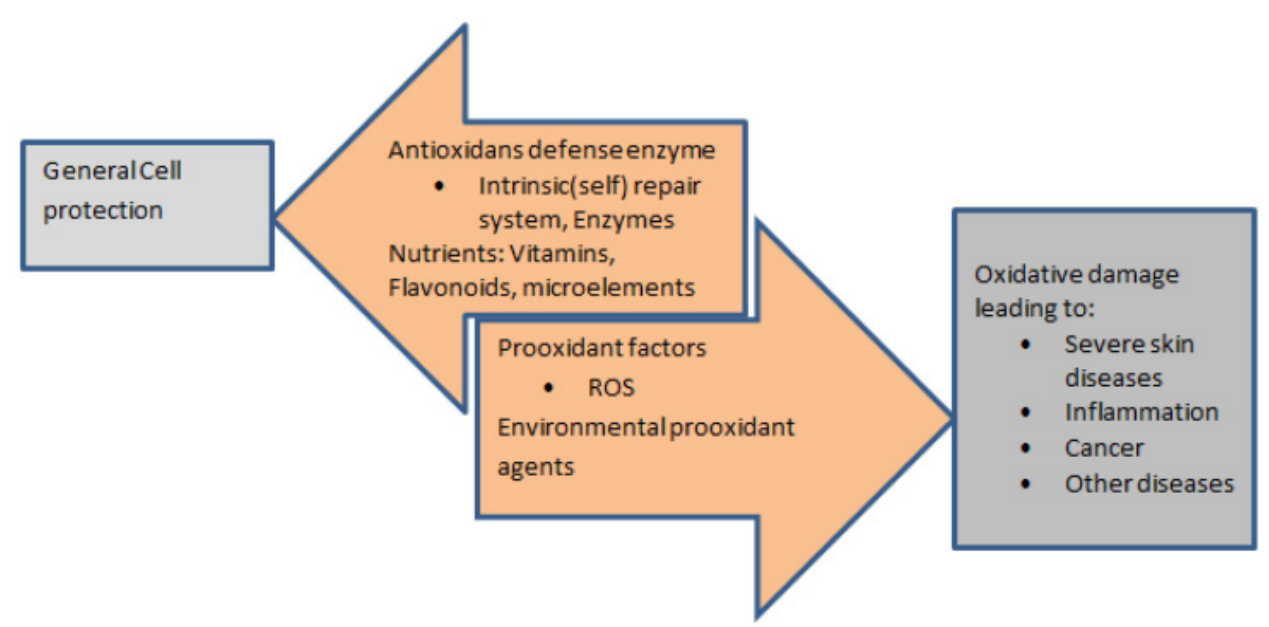

Figure 2: Mechanism of ROS resulting in inflammation [40-43]. 
Table 2: List of drugs under trials

\begin{tabular}{|c|c|c|c|c|c|}
\hline Type & Investigational Drug & Intended Actions & Clinical trial phase & Dosage form & $\begin{array}{l}\text { Refer- } \\
\text { ences }\end{array}$ \\
\hline \multirow{3}{*}{$\begin{array}{l}\text { Erythematotelangi- } \\
\text { ectatic rosacea }\end{array}$} & Laropiprant & Human prostaglandin D2 receptor-1 & Early phase & Topical & {$[52]$} \\
\hline & & & (On hold) & & \\
\hline & Aganirsen & Antisense oligonucleotide & Early phase & Topical & {$[53]$} \\
\hline \multirow[t]{8}{*}{$\begin{array}{l}\text { Papulopustular } \\
\text { rosacea }\end{array}$} & $\begin{array}{l}\text { Omiganan pentahydrochlo- } \\
\text { ride }\end{array}$ & Disruption of the cytoplasmic membranes & Phase III & Topical & {$[60,61]$} \\
\hline & Ivermectin $1 \%$ cream & $-n / a-$ & Phase III completed & Topical & [55] \\
\hline & Carbamide peroxide & Inhibiting inflammatory mediators & Phase III completed & Topical & {$[62]$} \\
\hline & SGT-VD-54 & $-n / a-$ & Phase II & Topical & [62] \\
\hline & Sarecycline hydrochloride & $\begin{array}{l}\text { Down regulates inflammatory cytokine } \\
\text { production }\end{array}$ & Phase II & Oral & {$[63]$} \\
\hline & Apremilast & $\begin{array}{l}\text { Modulates multiple anti-inflammatory } \\
\text { pathways }\end{array}$ & Phase II completed & Oral & {$[56]$} \\
\hline & Azelaic acid foam & & Phase III ongoing & $\begin{array}{l}\text { Topical Author } \\
\text { et. al }\end{array}$ & {$[57]$} \\
\hline & Incobotulinumtoxin A & $-n / a-$ & Phase II & I.V & {$[58,64$} \\
\hline Phymatous Rosacea & No specific drug under trials & $-n / a$ & & & \\
\hline Ocular Rosacea & No specific drug under trials & $-n / a-$ & & & \\
\hline
\end{tabular}

$-\mathrm{n} / \mathrm{a}-=$ Not available; I.V = Intravenous

\section{Ferritin levels and Oxidative damage}

The Iron levels in body specifically at cellular level should be maintained, as it catalyzes the conversion of hydrogen peroxide to free radicals leading to tissue injury by damaging cellular membranes, more specifically the proteins and DNA. Iron that is not metabolized is stored as ferritin at the cellular level [35]. In a recent study, the biopsy specimens of skin from patients with rosacea were immune-histo-chemically analyzed, and the number of ferritin-positive cells was significantly higher in affected individuals compared with control subjects [36]. Moreover, the higher ferritin positivity in cells is linked with advanced subtypes of rosacea. And so, we can say that pathogenesis of rosacea is interdependent on free iron release (proteolysis) of ferritin resulting in oxidative damage to the skin [37].

\section{What are the ongoing drug trials on Rosacea?}

In August 2013, the topical form of the alpha-2 agonist brimonidine [44] became the first Food and Drug Association (FDA)-approved topical treatment developed and indicated specifically for rosacea-associated facial erythema. The medication, which was approved for adults aged 18 years or older, was assessed using 2 phase 3 clinical studies (short-term), involving a total of 550 patients, as well as a long-term study (up to 12 months) in 276 subjects [44]. The most common adverse events (i.e., those affecting at least $4 \%$ of patients) in the long-term trial included flushing $(10 \%)$, erythema $(8 \%)$, rosacea $(5 \%)$, nasopharyngitis $(5 \%)$, skin burning sensation $(4 \%)$, increased intraocular pressure $(4 \%)$, and headache $(4 \%)$.

Furthermore, the treatment gap will soon be narrowed, thanks to the development of novel thera- pies that are specifically designed to address the problem of redness. In addition, other agents in the pipeline should further improve the arsenal of treatments for the papules and pustules of rosacea.

In the year 2013, many new therapies are currently in various clinical evaluation phases (Table 2) for the treatment of patients with rosacea and a few more are in preclinical and laboratory testing stage. The novel compounds are expected to provide clinically improvements in the treatment of patients with rosacea the papulopustular, erythemato-telangiectatic types, thereby bridging the gap by addressing the erythema component of rosacea, where current approaches fall short.

Furthermore, American academy of Dermatologists (AAD) in 2013 proposed the use of probiotics in treating rosacea [66]. The hypothesis was based on "Bacterial interferences." The probiotics, with living microorganisms are known for their positive effects. When applied topically on rosacea or acne prone area of skin (site), the immune system recognizes them as foreign particle and acts at site, thus reducing inflammation, redness, or bumps. And also, a couple of small-scale trials one conducted in Korea and other in Italy, showed promising results in effective clearing of rosacea and acne symptoms [67-68].

\section{Discussion}

This review identified 14 key studies (Table 1) on different pathophysiologies of rosacea. Apart from randomized control trials, there were comparative, observational, diagnostic trials were included. No adverse events were reported from any of the study; however confirmation of specific or exact single cause for the disease was a limitation of the review. Each cause identified here could possibly act as precursors, 
a bridge between and amongst all the caused.

Firstly, exposure to sunlight could trigger the disease to the people whose skin is too sensitive and prone to rosacea. Guzman-Sanchez et al [18] in a comparative $(n=24)$, multicenter, cross-sectional trial conducted in USA for over a year to assess the heat pain threshold and dermal vascularity with 8 healthy controls (HCs) and 16 rosacea patients. This study showed enhanced sensitivity to noxious heat stimuli in rosacea-affected skin, which was more prominent in the PPR group $(P<.05)$. By this study, it can be said that there is a correlation between heat and vascularity in rosacea.

Cribier et al. [19] conducted a diagnostic trial in France among patients \& HCs $(n=86)$, on relation vascularity and inflammation. The study revealed that vasculature and inflammatory responses are interrelated and aiding in pathology of rosacea. The result of excess of blood supply leads to hyper-erythema.

In 2006, Smith et al. [50] conducted a trial to study the vascular endothelial growth factor (VEGF) expression levels in rosacea patients (vascular endothelium and mononuclear blood cells). All the patients $(n=20)$ were diagnosed with rosacea, the biopsy specimens were collected and immuno-stained to identify the expressions of VEGF, VEGF-R1, VEGF-R2 using indirect method using antigen retrieval. The VEGF-R1, R2 receptors frequently stained positive but infrequently in case of VEGF. And in case of lymphocytes, macrophages and plasma cells, all three receptors are very well expressed $(P=0.005)$. VEGF receptors-binding-ligands may contribute in vascular and cellular changes in the rosacea patients. In comparison with the studies conducted by Guzman-Sanchez et al [18] and Cribier et al. [19] with Smith et al, there is surely a connection between vasculature, inflammation, immune responses and rosacea.

In a study conducted by LE Heuzey et al. [21] to assess the effects of chemical agents on skin redness/flush, it was evident that external agents have a role in pathophysiology of rosacea. Here, dronedarone and amiodarone (antiarrhythmic agents) were checked on rosacea patients/HCs. There was a significant rise in the redness/flush $(\mathrm{n}=504, P=0.129)$ on the skin and thus it contributes to rosacea. Though there is no significant evidence that food items aid in disease, however it cannot be ruled out.

The potential role of ROS was measured by Bakar et al [39]. The study is an unprecedented ex vivo study $(n=42)$ to support the role of ROS in rosacea. The ROS levels when compared to HCs were much higher in rosacea patients. Ferritin levels, oxidative damage in rosacea were measured by Tisma et al [36].
The RCT was conducted $(n=71, H C=11)$ using the blood samples and measuring the serum peroxidases and serum antioxidative potential levels. The serum peroxidase levels were significantly higher in the rosacea patients, which helps in release free iron ions and increase the oxidative stress and ferritin expression.

Cathelicidin levels in rosacea patients were higher than HCs in study conducted by Coda et al [32]. The study $(n=55, H C=5)$ measured the serine protease activity and correlated the levels of the cathelicidin levels. Rosacea can be averted in the early stages was shown in the trial conducted by Tsiskarishvili et al [49]. The observational study $(n=50)$ conducted on beta-blockers and rozaliak in early stage rosacea condition. Both beta-blockers and rozaliak had a positive effect in rosacea treatment during the early stage diagnosis.

The potential role of microorganisms in pathophysiology of rosacea is still a debate. However, the various studies conducted on possible role of Demodex and H. Pylori in rosacea were scientifically significant. Jarmuda et al. [25] conducted a controlled trial $(n=127)$ to measure the level of demodex mites on facial skin. All the skin samples were collected from patients, HCs and checked the presence of demodex. The percentage of demodex mites in rosacea patients was much higher when compared to HCs. A similar result was obtained in another study conducted by Casas et al [24]. The demodex levels in rosacea patients $(n=98)$ in correlation to their immune responses were measured. The density of demodex in rosacea patients was 5.7 times higher than HCs $(P=$ 0.05).

With regards to $\mathrm{H}$. Pylori, many studies were conducted to assess the role in rosacea. All the studies were nor inconclusive nor affirming the role of $\mathrm{H}$. Pylori in rosacea. Sherif et al [28] conducted a RCT $(n=$ 36) on relation of sunlight on $\mathrm{H}$. Pylori in rosacea. Here, exposure to sunlight, vasculature and inflammatory response acts as a trigger point to gut bacteria stimulating rosacea. The role of bacteria is still unknown. However, in another study randomized trial conducted by Parodi et al. [66] demonstrated that there is highly significant number of $\mathrm{H}$. Pylori in the gut of the rosacea patients $(n=53)$ when compared to HCs $(n=60)(P<0.001)$. Eradication of small intestinal bacterial overgrowth state and normalization of the intestinal flora via the antibiotic rifaximin led to improvement of rosacea.

Brown et al. [48] conducted a comparative trial $(n=57)$ between rosacea and cutaneous Lupus erythematosus (LE) to measure the chronic immune activation phenomena. Chronic immune activation leads to mild-severe inflammations giving rise to se- 
vere skin disorders. In this study the role of T-cells (acquired immune subsets) was assessed. Interestingly, the T-cell mediated responses have a significant role in rosacea and LE conditions. Thus, we can say immune responses are responsible for disease with vasculature.

The rosacea progression was also associated with sub-types. Tan J et al. [46] conducted an observational, cross sectional survey amongst patients $(\mathrm{n}=$ 135) who are diagnosed with different types of rosacea. The clinical association and progression of rosacea amongst the various sub-types was evident $(P=0.005)$.

Rosacea, the most intricate disease, has multiple pathologies involving prominent vascular and inflammatory response factors. Characteristic small blood vessels, mononuclear blood cells, perivascular inflammation come into account of histology. Various environmental triggers involving exposure to sunlight, temperature change have a prominent role in the disease. The role of microorganisms was explained with weight of evidence. Figure 3 explains the

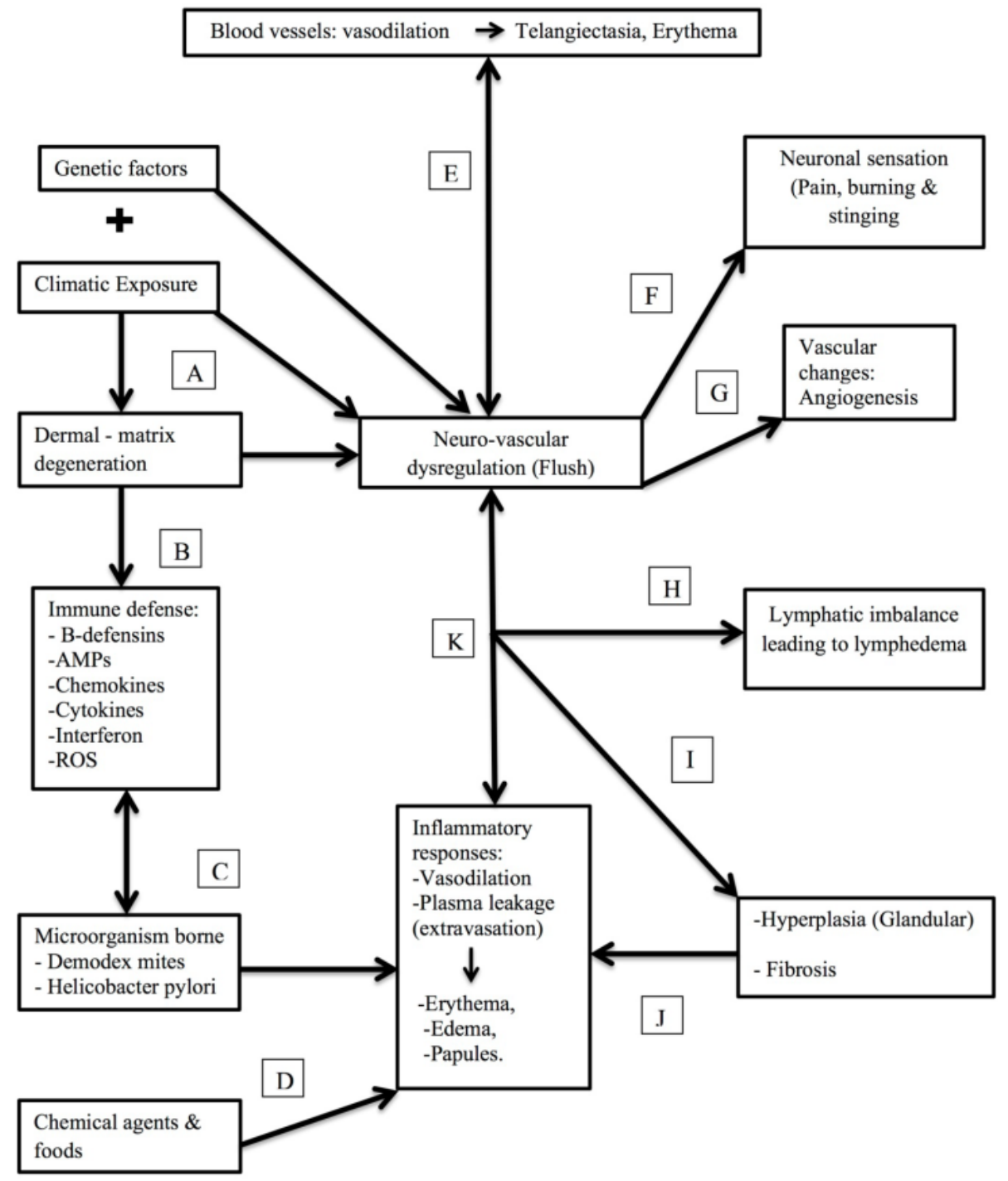

whole pathophysiology, how each factor singly or cumulatively responsible for disease.

Demodex mites presence stimulates the inflammatory response with help of bacteria degradation in the body. Any alteration or abnormality in vascular system, leads to dilation of blood vessels which happens to be a favorable conditions for demodex to colonize and thrive. The presence of high number demodex mites leads to activation of various inflammatory responses resulting in appearing of initial symptoms of the disease. The chronic inflammatory responses in turn help in release of oxygen free radicals leading to dermal matrix damage and blood vessel damage. The release of oxygen free radicals, blood vessel damage and additional inflammatory responses can possibly result in over expression of pro-inflammatory peptides such as cathelicidins. Apart from the mentioned factors, psychological factors such as stress, anxiety and depression can also be responsible for rosacea. The psychological factors either alone or in combination with the consumption of processed comfort foods alters the gastrointestinal flora, which in turn leads to increased intestinal permeability.

Figure 3: The presumed pathophysiology of rosacea in correlation with specific molecular, immunological, neuronal and clinical triggers. (A) Recurrent exposure to extreme sunlight (environmental changes) causes the dermal matrix degeneration, which in turn may trigger genetic predisposition leading to hypersensitivity and flush on the skin. (B) As a part of hypersensitivity, it triggers the innate immune response. (C) Effect of microorganisms like Demodex and Helicobacter pylori gives rise to the several inflammatory responses in the body. (D) Chemical and food agents would also trigger inflammatory responses. (E) Vasodilation of blood vessels by immune responses that may lead to Telangiectasia, Erythema. (F) Neural activation results in vasodilatation, edema and burning sensation (G) Chronic neurogenic inflammation may lead to persistent erythema, followed by angiogenesis. $(\mathrm{H})$ Imbalance in lymphatic system leads to lymphedema followed (I) Glandular hyperplasia and fibrosis $(\mathrm{J})$ leading to inflammatory responses like vasodilation, extravasation and plasma leakage (severe case) giving rise to $(K)$ erythema, edema and papules. 


\section{Conclusion}

In conclusion, we can say that there are multiple factors responsible for the disease. All the present treatment options and forthcoming therapies are based on symptoms. There is still need for high quality RCTs targeting clinical, cellular and molecular pathophysiological relations to rosacea. Future trials should address methodological limitations, including sample size, recruitment and adherence as well as detailed characterization of clinical disease correlation in rosacea condition and duration.

\section{Acknowledgements}

The authors would like to thank the University of Malaya for supporting this research through University of Malaya Research Grant UMRG (UMRG; RP021B-13HTM).

\section{Competing Interest}

Authors have declared that no competing interest exists.

\section{References}

1. Coleman WP. Acne and Rosacea: Epidemiology, Diagnosis, and Treatment. London, UK: Manson Publishing Ltd; 2012: 1-96.

2. Baldwin HE. Diagnosis and treatment of rosacea: state of the art. J Drugs Dermatol. 2012; 11: 725-30.

3. Maier LE. Rosacea: advances in understanding pathogenesis and treatment. J Clin Invest. 2011; 1: 739-55.

4. Abram K, Silm H, Maaroos HI, Oona M. Risk factors associated with rosacea. J Eur Acad Dermatol Venereol. 2010; 24: 565-71. doi: 10.1111/j.1468-3083.2009.03472.x.

5. Gallo RL, Nakatsuji T. Microbial symbiosis with the innate immune defense system of the skin. J Invest Dermatol. 2011; 131: 1974-80. doi: 10.1038/jid.2011.182.

6. Misery L, Sibaud V, Merial-Kieny C, Taieb C. Sensitive skin in the American population: prevalence, clinical data, and role of the dermatologist. Int J Dermatol. 2011; 50: 961-67. doi: 10.1111/j.1365-4632.2011.04884.x.

7. Del Rosso JQ. Advances in understanding and managing rosacea: part 1 : connecting the dots between pathophysiological mechanisms and common clinical features of rosacea with emphasis on vascular changes and facial erythema. J Clin Aesthet Dermatol. 2012; 5: 16-25.

8. Okhovat JP, Armstrong AW. Updates in Rosacea: Epidemiology, Risk Factors, and Management Strategies. Curr Dermatol Rep. 2014; 3: 23-28.

9. İkizoğlu G. The Red Face Revisited: Flushing. Clin Dermatol. 2014; 32: 800-8. doi: 10.1016/j.clindermatol.2014.02.019.

10. Chauhan N, Ellis DA. Rosacea: Pathophysiology and Management Principles. Facial Plast Surg Clin North Am. 2013; 21: 127-36. doi: 10.1016/j.fsc.2012.11.004

11. Fleischer $A B$ Jr. Inflammation in rosacea and acne: Implications for patient care. J Drugs Dermatol. 2011; 10: 614-20.

12. Steinhoff M, Schauber J, Leyden JJ. New insights into rosacea pathophysiology: A review of recent findings. J Am Acad Dermatol. 2013; 69 (Suppl 1): S15-S26. doi: 10.1016/j.jaad.2013.04.045.

13. Robert AN, Edward MY Jr. Rosacea. In: Atlas of Geriatric Dermatology, part II. London: Springer; 2014:103-109.

14. Feldman SR, Huang WW, Huynh TT. Current Drug Therapies for Rosacea: A Chronic Vascular and Inflammatory Skin Disease. J Manag Care Pharm. 2014; 20: 623-9.

15. McAleer MA, Fitzpatrick P, Powell FC. Papulopustular rosacea: prevalence and relationship to photodamage. J Am Acad Dermatol. 2010; 63: 33-9.

16. Crawford GH, Pelle MT, James WD. Rosacea: I. Etiology, pathogenesis, and subtype classification. J Am Acad Dermatol. 2004; 51: 327-41.

17. Buechner SA. Rosacea: an update. Dermatology. 2005; 210: 100-8

18. Guzman-Sanchez DA, Ishiuji Y, Patel T, Fountain J, Chan YH, et al. Enhanced skin blood flow and sensitivity to noxious heat stimuli in papulopustular rosacea. J Am Acad Dermatol. 2007; 57: 800-5.

19. Cribier B. Rosacea under the microscope: characteristic histological findings. J Eur Acad Dermatol Venereol. 2013; 27: 1336-43. doi: 10.1111/jdv.12121.

20. Clare M, Johnson PE, Zuidmeer-Jongehan L, Ross C, et al. Effect of Processing on the Allergenicity of Foods. In: Color DP, ed. Risk Management for Food
Allergy. Acad press: Food science and Technology series, Elsevier Science \& Technology Books. 2014: 227.

21. Le Heuzey JY, De Ferrari GM, Radzik D, Santini M, Zhu J, et al. A Short-Term, Randomized, Double-Blind, Parallel-Group Study to Evaluate the Efficacy and Safety of Dronedarone versus Amiodarone in Patients with Persistent Atrial Fibrillation: The DIONYSOS Study. J Cardiovasc Electrophysiol. 2010; 21: 597-605. doi:10.1111/j.1540-8167.2010.01764.x.

22. Bonnar E, Eustace P, Powell FC. The Demodex mite population in rosacea. J Am Acad Dermatol. 1993; 28: 443-8.

23. Rather PA, Hassan I. Human demodex mite: The versatile mite of dermatological importance. Indian J Dermatol. 2014; 59: 60-6. doi: 10.4103/0019-5154.123498.

24. Casas C, Paul C, Lahfa M, Livideanu B, Lejeune O, et al. Quantification of Demodex folliculorum by PCR in rosacea and its relationship to skin innate immune activation. Exp Dermatol. 2012; 21: 906-10. doi: 10.1111/exd.12030.

25. Jarmuda S, McMahon F, Zaba R, O'Reilly N, Jakubowicz O, et al. Correlation between serum reactivity to Demodex-associated Bacillus oleronius proteins, and altered sebum levels and Demodex populations in erythematotelangiectatic rosacea patients. J Med Microbiol. 2014; 63: 258-62. doi: 10.1099/jmm.0.065136-0.

26. Kutlubay Z, Zara T, Engin B, Serdaroğlu S, Tüzün Y, et al. Helicobacter pylori infection and skin disorders. Hong Kong Med J. 2014; 20: 317-24. doi: $10.12809 / \mathrm{hkmj} 134174$.

27. El-Sherif NA, El-Dibany SA. Clinical evaluation of Libyan patients with rosacea and its correlation with seropositivity to Helicobacter pylori. Journal of Dermatology \& Dermatologic Surgery. 2014; 18: 1-2. doi: 10.1016/j.jssdds.2013.12.005

28. Roby KD, Nardo AD. Innate immunity and the role of the antimicrobial peptide cathelicidin in inflammatory skin disease. Drug Discov Today Dis Mech. 2013; 10: e79-e82.

29. Muto Y, Wang Z, Vanderberghe M, Two A, Gallo RL, et al. Mast Cells are Key Mediators of Cathelicidin Initiated Skin Inflammation in Rosacea. J Invest Dermatol 2014; 134: 2728-36. doi: 10.1038/jid.2014.222.

30. Schauber J, Gallo RL. Antimicrobial peptides and the skin immune defense system. J Allergy Clin Immunol. 2008; 122: 261-6. doi: 10.1016/j.jaci.2008.03.027.

31. Salvado MD, Di Gennaro A, Lindbom L, Agerberth B, Haeggström JZ. Cathelicidin LL-37 Induces Angiogenesis via PGE2-EP3 Signaling in Endothelial Cells, In Vivo Inhibition by Aspirin. Arterioscler Thromb Vasc Biol. 2013; 33: 1965-72. doi: 10.1161/ATVBAHA.113.301851.

32. Coda AB, Hata T, Miller J, Audish D, Kotol P, et al. Cathelicidin, kallikrein 5, and serine protease activity is inhibited during treatment of rosacea with azelaic acid 15\% gel. J Am Acad Dermatol. 2013; 69: 570-77. doi: 10.1016/j.jaad.2013.05.019.

33. Santos JC, Silva-Gomes S, Silva JP, Gama M, Rosa G, et al. Endogenous cathelicidin production limits inflammation and protective immunity to Mycobacterium avium in mice. Immun Inflamm Dis. 2014; 2: 1-12. doi: 10.1002/iid3.7.

34. Zhang J, Xu X, Rao NV, Argyle B, McCoard L, et al. Novel Sulfated Polysaccharides Disrupt Cathelicidins, Inhibit RAGE and Reduce Cutaneous Inflammation in a Mouse Model of Rosacea. PLoS ONE. 2011; 6: e16658. doi: 10.1371/journal.pone.0016658.

35. Zhang XZ, Su AL, Hu MQ, Zhang XQ, Xu YL. Elevated serum ferritin levels in patients with hematologic malignancies. Asian Pac J Cancer Prev. 2014; 15: 6099-101.

36. Tisma VS, Basta-Juzbasic A, Jaganjac M, Brcic L, et al. Oxidative stress and ferritin expression in the skin of patients with rosacea. J Am Acad Dermatol. 2009; 60: 270-6. doi: 10.1016/j.jaad.2008.10.014.

37. Leiva E, Mujica V, Sepúlveda P, Guzmán L, Núñez S, et al. High levels of iron status and oxidative stress in patients with metabolic syndrome. Biol Trace Elem Res. 2013; 151: 1-8. doi: 10.1007/s12011-012-9525-3.

38. Jones DA. Rosacea, reactive oxygen species, and azelaic acid. J Clin Aesthetic Derm. 2009; 2: 26-30.

39. Bakar O, Demirçay Z, Yuksel M, Haklar G, Sanisoglu Y. The effect of azithromycin on reactive oxygen species in rosacea. Clin Exp Dermatol. 2007; 32: $197-200$.

40. Esser PR, Wölfle U, Dürr C, von Loewenich FD, Schempp CM, et al. Contact sensitizers induce skin inflammation via ROS production and hyaluronic acid degradation. PloS one. 2012; 7: e41340. doi: 10.1371/journal.pone.0041340.

41. Nakai K, Yoneda K, Kubota Y. Oxidative Stress in Allergic and Irritant Dermatitis: From Basic Research to Clinical Management. Recent Pat Inflamm Allergy Drug Discov. 2012; 6: 202-9.

42. Korkina L, Pastore S. The role of redox regulation in the normal physiology and inflammatory diseases of skin. Front Biosci (Elite Ed). 2009; 1: 123-41.

43. Pillai S, Oresajo C, Hayward J. Ultraviolet radiation and skin aging: Roles of reactive oxygen species, inflammation and protease activation, and strategies for prevention of inflammation-induced matrix degradation - A review. Int J Cosmet Sci. 2005; 27: 17-34. doi: 10.1111/j.1467-2494.2004.00241.x.

44. Zhuang Y, Lyga J. Inflammaging in Skin and other Tissues - the Roles of Complement System and Macrophage. Inflamm Allergy Drug Targets. 2014; 13: 153-61.

45. Roby KD, Nardo AD. Innate immunity and the role of the antimicrobial peptide cathelicidin in inflammatory skin disease. Drug Discov Today. 2013; 10: e79-e82. 
46. Tan J, Blume-Peytavi U, Ortonne JP, Wilhelm K, Marticou L, et al. An observational cross-sectional survey of rosacea: clinical associations and progression between subtypes. $\mathrm{Br} \mathrm{J}$ Dermatol. 2013; 169: 555-62. doi: $10.1111 /$ bjd. 12385

47. Schauber J, Gallo RL. Antimicrobial peptides and the skin immune defense system. J Allergy Clin Immunol. 2008; 122: 261-6.

48. Brown TT, Choi EY, Thomas DG, Hristov AC, Chan MP. Comparative analysis of rosacea and cutaneous lupus erythematosus: Histopathologic features, T-cell subsets, and plasmacytoid dendritic cells. J Am Acad Dermatol. 2014; 71: 100-7. doi: 10.1016/j.jaad.2014.01.892.

49. Tsiskarishvili NV, Katsitadze A, Tsiskarishvili Ts. New possibilities in the treatment of early stages of rosacea. Georgian Med News. 2013; 214: 23-8.

50. Smith JR, Lanier VB, Braziel RM, Falkenhagen KM, White C, et al. Expression of vascular endothelial growth factor and its receptors in rosacea. $\mathrm{Br} \mathrm{J} \mathrm{Oph-}$ thalmol. 2007; 91: 226-9.

51. Tong LX, Moore AY. Brimonidine tartrate for the treatment of facial flushing and erythema in rosacea. Expert Rev Clin Pharmacol. 2014; 7: 1-11. doi: $10.1586 / 17512433.2014 .945910$

52. Haynes R, Jiang L, Hopewell JC, Li J, Chen F, et al. HPS2-THRIVE randomized placebo-controlled trial in 25673 high-risk patients of ER niacin/laropiprant: trial design, pre-specified muscle and liver outcomes, and reasons for stopping study treatment. Eur Heart J. 2013; 34: 1279-91. doi: 10.1093/eurheartj/eht055.

53. Colin S, Darné B, Kadi A, Ferry A, Favier M, et al. The Antiangiogenic Insulin Receptor Substrate-1 Antisense Oligonucleotide Aganirsen Impairs AU-Rich mRNA Stability by Reducing 14-3-3 $\beta$-Tristetraprolin Protein Complex, Reducing Inflammation and Psoriatic Lesion Size in Patients. J Pharmacol Exp Ther. 2014; 349: 107-17. doi: 10.1124/jpet.113.209346.

54. Fowler J, Tan J, Jackson JM, Meadows K, Jones T, et al. Treatment of facial erythema in patients with rosacea with topical brimonidine tartrate: correlation of patient satisfaction with standard clinical endpoints of improvement of facial erythema. J Eur Acad Dermatol Venereol. 2015; 29: 474-81. doi: 10.1111/jdv.12587 833- 985

55. Stein L, Kircik L, Fowler J, Tan J, Draelos Z, et al. Efficacy and safety of ivermectin $1 \%$ cream in treatment of papulopustular rosacea: results of two randomized, double-blind, vehicle-controlled pivotal studies. J Drugs Dermatol. 2014; 13: 316-23.

56. Thompson BJ, Furniss M, Zhao W, Chakraborty B, Mackay-Wiggan J. An Oral Phosphodiesterase Inhibitor (Apremilast) for Inflammatory Rosacea in Adults: A Pilot Study. JAMA Dermatol. 2014; 150: 1013-4. doi: 10.1001/jamadermatol.2013.10526.

57. Draelos ZD, Elewski B, Staedtler G, Havlickova B. Azelaic acid foam $15 \%$ in the treatment of papulopustular rosacea: a randomized, double-blind, vehicle-controlled study. Cutis. 2013; 92: 306-17.

58. Kim BJ, Kwon HH, Park SY, Min SU, Yoon JY, et al. Double-blind, randomized non-inferiority trial of a novel botulinum toxin A processed from the strain CBFC26, compared with onabotulinumtoxin A in the treatment of glabellar lines. J Eur Acad Dermatol Venereol 2014; 28: 1761-7. doi: 10.1111/jdv.12408

59. Sader HS, Fedler KA, Rennie RP, Stevens S, Jones RN. Omiganan pentahydrochloride (MBI 226), a topical 12-amino-acid cationic peptide: spectrum of antimicrobial activity and measurements of bactericidal activity. Antimicrob Agents Chemother. 2004; 48: 3112-8

60. [Internet] ClinicalTrials, A service of the US National Institutes of Health. http://clinicaltrials gov/show/NCT01784133.

61. [Internet] David P. Rosacea Support Group. http://rosacea-support.org/ omiganan-cls001-dose-finding-trials.html

62. [Internet] Caroline H. http://www.ahdbonline.com/payer-perspectivesin-dermatology/1570-emerging-therapies-for-the-treatment-of-rosacea.

63. [Internet] Research and Markets: Global Rosacea Therapeutic Pipeline Review 2014. http://uk.reuters.com/article/2014/04/28/research-and-marketsidUKnBw286084a+100+BSW20140428.

64. Imhof M, Kühne U. A phase III study of incobotulinumtoxinA in the treatment of glabellar frown lines. J Clin Aesthet Dermatol. 2011; 4: 28-34.

65. [Internet] American Academy of Dermatology, Schaumburg, 2014. http://www.aad.org/stories-and-news/news-releases/could-probiotics-be-t he-next-big-thing-in-acne-and-rosacea-treatments.

66. Parodi A, Paolino S, Greco A, Drago F, Mansi C, et al. Small intestinal bacterial overgrowth in rosacea: clinical effectiveness of its eradication. Clin Gastroenterol Hepatol. 2008; 6: 759-64. doi: 10.1016/j.cgh.2008.02.054.

67. Kim J, Ko Y, Park YK, Kim N, Ha WK, et al. Dietary effect of lactoferrin-enriched fermented milk on skin surface lipid and clinical improvement of acne vulgaris. Nutrition. 2010; 26: 902-9. doi: 10.1016/j.nut.2010.05.011.

68. Bowe W, Patel NB, Logan AC. Acne vulgaris, probiotics and the gut-brain-skin axis: from anecdote to translational medicine. Benef Microbes. 2014; 5: 185-99. doi: 10.3920/BM2012.0060. 